\title{
Relationship between Plasma Cortisol Levels and Stress Ulcer following Acute and Severe Head Injury
}

\author{
Zhong-Min Li ${ }^{\mathrm{a}}$ Le-Xin Wang ${ }^{\mathrm{b}} \quad$ Li-Cheng Jiang $^{\mathrm{a}} \quad$ Jian-Xin Zhu ${ }^{\mathrm{a}}$ \\ Feng-Yang Geng ${ }^{\text {a }}$ Fu Qiang ${ }^{\text {a }}$ \\ ${ }^{a}$ Department of Neurosurgery, Liaocheng People's Hospital and Liaocheng Clinical School of Taishan Medical \\ University, Liaocheng, PR China; ${ }^{b}$ School of Biomedical Sciences, Charles Sturt University, Wagga Wagga, N.S.W., \\ Australia
}

\section{Key Words}

Head injury $\cdot$ Stress ulcer $\cdot$ Cortisol

\begin{abstract}
Objective: This study was designed to investigate the relationship between plasma cortisol levels and stress ulcer following acute severe head injury. Patients and Methods: The plasma cortisol levels were prospectively measured by radioimmunoassay in 68 patients following acute head injury. The diagnosis of stress ulcer was based on clinical evidence and was confirmed by endoscopic examination. Results: Patients with stress ulcer and gastrointestinal bleeding $(n=30,44.1 \%)$ were older than those without stress ulcer ( $38.2 \pm 7.9 \mathrm{vs} .28 .3$ \pm 9.7 years, $p<0.01)$. The combined rate of poor recovery and death in the stress ulcer patients (70.0\%) was significantly higher than in the nonulcer patients $(42.1 \%, p=0.02)$. On each of the first 3 days following the head injury, the average plasma cortisol levels in the stress ulcer patients were higher than in the nonulcer patients $(p<0.01)$. Univariate analysis showed a positive relationship between plasma cortisol on admission and stress ulcer $(r=0.329, p=0.01)$. Logistic regression analysis revealed that plasma cortisol levels on admission $(\mathrm{OR}=2.326,95 \% \mathrm{Cl}=1.982-2.466)$ and age $(\mathrm{OR}=1.064$,
\end{abstract}

$95 \% \mathrm{Cl}=0.861-1.219)$ were independent predictors of stress ulcer. Conclusions: The data showed that acute severe head injury was associated with a significant increase in plasma cortisol. Plasma levels of cortisol and age were independent predictors of stress ulcer following acute head injury.

Copyright $\odot 2009$ S. Karger AG, Basel

\section{Introduction}

Acute traumatic head or brain injury is the leading cause of death and severe disability in people under 45 years of age $[1,2]$. One of the major complications following acute head injury is gastrointestinal ulcer (stress ulcer). The prevalence of stress ulcers has been reported to be between 40 and $80 \%$ following severe head injuries [3-7].

The causes of stress ulcer following head injury are complex and several factors may be involved. It has been postulated that hypermetabolic responses, elevated cytokine activity, liver dysfunction, and gut ischemia may contribute to the pathogenesis of stress ulcer [8-12]. High incidence of tissue endothelin-1 expression combined with increased activity of inducible nitric oxide synthase

\section{KARGER}

Fax +41613061234 E-Mail karger@karger.ch www.karger.com
(C) 2009 S. Karger AG, Base

$1011-7571 / 10 / 0191-0017 \$ 26.00 / 0$

Accessible online at:

www.karger.com/mpp
Prof. Le-Xin Wang

School of Biomedical Sciences

Charles Sturt University

Wagga Wagga, N.S.W. 2678 (Australia)

Tel. +61 26933 2905, Fax +61 26933 2587, E-Mail lwang@csu.edu.au 
may also be involved in the pathogenesis of gastric mucosal injuries [13].

Acute head injuries have a significant impact on the secretion of some hormones. The hypothalamic-pituitary-adrenocortical system is often activated following head trauma, with a significant increase in plasma cortisol levels $[14,15]$. However, whether or not the elevation of cortisol is responsible for stress ulcer is unclear. In the present study, we prospectively measured the plasma levels of cortisol and assessed the prevalence of stress ulcer and gastrointestinal bleeding in a group of patients with acute severe head injury. The relationship between the plasma cortisol and stress ulcer was subsequently analyzed.

\section{Patients and Methods}

\section{Patient Selection}

This study was approved by the institutional review board of Liaocheng People's Hospital. Informed consent was obtained from all participants or their relatives. During a period of 12 months, 68 patients admitted to Liaocheng People's Hospital were prospectively recruited to this study. There were 42 males and 26 females, with an average age of $33.7 \pm 12.1$ years (range, $12-71$ ). All patients sustained severe head injury and were admitted within $6 \mathrm{~h}$ after the insult.

The selection criteria were: (a) acute severe head or brain injury with a Glasgow Coma Scale (GCS) score of $\leq 8$ within $6 \mathrm{~h}$ of the injury; (b) no injuries to other organs apart from the head or brain, and no history of other acute or chronic illnesses; (c) no medication history such as the use of corticosteroids or nonsteroid anti-inflammatory drugs prior to the head injury. Excluded were patients with any coexisting trauma, or with preexisting peptic ulcer, or patients who died within $48 \mathrm{~h}$ after the trauma.

The causes of the head injuries were as follows: road accident $(\mathrm{n}=38)$, fall from heights and injury from heavy impact $(\mathrm{n}=30)$. The types of the head injuries included epidural hematoma ( $\mathrm{n}=$ $18)$; subdural hematoma $(n=27)$; cerebral bleeding $(n=12)$; brain contusion $(n=40)$; primary brain stem trauma $(n=3)$; traumatic subarachnoid bleeding $(\mathrm{n}=43)$; acute brain swelling $(\mathrm{n}=7)$, and skull fracture $(\mathrm{n}=25)$.

All patients underwent careful neurologic evaluation and received cranial computed tomographic scans on admission. Patients underwent emergency neurological surgeries or nonsurgical treatment according to the standard protocols of our hospital. Hyperventilation therapy and administration of mannitol were commonly given to prevent the elevation of intracranial pressure. Steroids were not used as part of the management. Patients with ulcerative bleeding were administered the proton pump inhibitor omeprazole intravenously. Thiopental or propofol was used in patients who required general anesthesia.

Diagnosis of Stress Ulcer

Diagnosis of stress ulcer was based on clinical evidence of gastrointestinal bleeding and reduction of blood hemoglobin. Endo- scopic examination was performed in patients with clinical evidence of stress ulcer to confirm the diagnosis.

\section{Measurement of Plasma Cortisol}

Venous blood ( $2 \mathrm{ml}$ at 8 a.m. and 5 p.m., respectively) was collected from each patient on the day of admission, daily during the first week of hospitalization, and finally on day 10 of the hospitalization. Cortisol radioimmunoassay kit (Assay Designs, Inc., Ann Arbor, Mich., USA) was used to measure the plasma cortisol level.

Patient Follow-Up

Patients were followed up at our hospital clinic monthly for up to 6 months. Recovery from head injury was classified as satisfactory (leading a normal life without the need for assistance from a caregiver), poor (severely disabled and requiring constant care) or death.

Statistical Analysis

Data were expressed as means \pm SD. SPSS version 13.0 was used for data analysis. Numerical data were analyzed with oneway ANOVA. The Mann-Whitney test was used to examine the difference in GCS scores between patients with and without stress ulcer; $\mathrm{p}<0.05$ was considered statistically significant.

A univariate analysis was performed to assess the correlation between the level of cortisol on admission and GCS scores. The cortisol levels on the first 3 days following the trauma were also compared between patients with and without stress ulcer. Logistic regression analysis was performed to assess the relationship between age, cortisol levels and stress ulcer.

\section{Results}

\section{General Findings}

Thirty-three patients underwent emergency neurological surgeries and 35 received nonsurgical treatment following the admission. Ulcerative upper gastrointestinal bleeding occurred in $30(44.1 \%)$ patients. No clinical evidence of ulcer was found in the remaining 38 (55.9\%) patients. There was no significant difference in sex between the two groups (table 1; $\mathrm{p}>0.05$ ), but patients with stress ulcer were older (table $1 ; \mathrm{p}<0.01$ ). All patients with ulcerative bleeding were managed by the proton pump inhibitor omeprazole for 5-7 days. Fresh blood transfusion was also administered in 9 patients.

\section{Comparison of GCS and Prognosis between the Ulcer and Nonulcer Groups}

As shown in table 1, the percentage of patients with a GCS score below 6 was higher in the stress ulcer group than in the nonulcer group (86.6 vs. $71.0 \%, p=0.03)$. The prognosis of patients with and without ulcer is shown in table 2 . Nine patients with stress ulcer and 5 without died $48 \mathrm{~h}$ after hospital admission. The combined rate of poor 
Table 1. GCS score in the ulcer and nonulcer patients

\begin{tabular}{lcc}
\hline & $\begin{array}{l}\text { Ulcer group } \\
(\mathrm{n}=30)\end{array}$ & $\begin{array}{l}\text { Nonulcer group } \\
(\mathrm{n}=38)\end{array}$ \\
\hline $\begin{array}{l}\text { Age, years } \\
\text { Male }\end{array}$ & $38.2 \pm 7.9$ & $28.3 \pm 9.7$ \\
Female & $24(80.0)$ & $32(84.2)$ \\
GCS score & $6(10.0)$ & $16(15.8)$ \\
$\quad 3-4$ & $10(33.3)$ & $7(18.4)$ \\
$5-6$ & $16(53.3)$ & $20(52.6)$ \\
$7-8$ & $4(13.3)$ & $11(28.9)$ \\
\hline
\end{tabular}

Figures in parentheses indicate percentages.
Table 2. Prognosis of the ulcer and nonulcer patients

\begin{tabular}{lcc}
\hline Prognosis & $\begin{array}{l}\text { Ulcer group } \\
(\mathrm{n}=30)\end{array}$ & $\begin{array}{l}\text { Nonulcer group } \\
(\mathrm{n}=38)\end{array}$ \\
\hline Satisfactory & $9(30)$ & $22(57.9)$ \\
Poor & $12(40)$ & $11(28.9)$ \\
Death & $9(30)$ & $5(13.2)$ \\
\hline Total & $30(100)$ & $38(100)$ \\
\hline
\end{tabular}

Figures in parentheses indicate percentages.

Table 3. Plasma cortisol in the ulcer and nonulcer patients

\begin{tabular}{|c|c|c|c|c|c|c|}
\hline \multirow[t]{2}{*}{ Patients } & \multicolumn{2}{|l|}{ Day 1} & \multicolumn{2}{|l|}{ Day 2} & \multicolumn{2}{|l|}{ Day 3} \\
\hline & 8 a.m. & 5 p.m. & 8 a.m. & 5 p.m. & 8 a.m. & 5 p.m. \\
\hline With ulcer $(\mathrm{n}=30)$ & $511.3 \pm 103.2^{*}$ & $475.6 \pm 108.7^{*}$ & $448.2 \pm 100.9^{*}$ & $421.4 \pm 110.6^{*}$ & $395.3 \pm 90.0^{*}$ & $380.8 \pm 87.5^{*}$ \\
\hline Without ulcer $(\mathrm{n}=38)$ & $432.8 \pm 110.2$ & $412.1 \pm 116.2$ & $380.1 \pm 95.3$ & $338.7 \pm 123.3$ & $280.4 \pm 93.6$ & $282.8 \pm 97.9$ \\
\hline
\end{tabular}

Reference plasma cortisol: 50-250 ng/ml. * $\mathrm{p}<0.01$ compared with patients without ulcer.

recovery and death was significantly higher in the patients with stress ulcer than in those without (70.0 vs. $42.1 \%, \mathrm{p}=0.02$ ).

\section{Comparison of Plasma Cortisol Levels between the \\ Ulcer and Nonulcer Groups}

The inter- and intraobserver variability of plasma cortisol testing was 4.5 and $5.2 \%$, respectively. The reference range of plasma cortisol in our laboratory was 50-250 ng/ $\mathrm{ml}$. Plasma levels of cortisol during the first 3 days of hospitalization are given in table 3. On day 1, in 59 (86.8\%) patients (all patients with stress ulcer and 29 patients without stress ulcer) the average plasma cortisol level was higher than the upper limit of the reference value (50-250 $\mathrm{ng} / \mathrm{ml}$ ). Pearson correlation analysis of the 68 patients showed a significant inverse relationship between the plasma cortisol levels on day 1 and the GCS scores ( $\mathrm{r}=$ $-0.635, \mathrm{p}<0.01)$. In $2(2.9 \%)$ patients, the plasma cortisol level was below $50 \mathrm{ng} / \mathrm{ml}$ ( 26 and $39 \mathrm{ng} / \mathrm{ml}$, respectively) during the first week of the head injury. The cortisol level returned to the normal reference range in both patients on day 10.
In comparison with the nonulcer patients (76.3\%), a greater proportion of those with stress ulcer $(100 \%)$ had an increased level of plasma cortisol $(\mathrm{p}<0.05)$. On each of the first 3 days, the average cortisol levels in the stress ulcer patients were higher than in the nonulcer patients $(p<0.01)$. The 10 -day variations of the average plasma cortisol levels in the stress ulcer and nonulcer patients are illustrated in figure 1 . There was a steady decline in the cortisol levels over time. After day 7, it had returned to the reference range.

\section{Relationship between Plasma Cortisol Levels and \\ Stress Ulcer}

Univariate analysis of the 68 patients showed a positive relationship between stress ulcer and plasma cortisol on day $1(\mathrm{r}=0.329, \mathrm{p}=0.01)$. There was also a modest but significant correlation between age and stress ulcer $(r=$ $0.232, p=0.04)$. Logistic regression analysis showed that the plasma cortisol levels on day $1(\mathrm{OR}=2.326,95 \% \mathrm{CI}=$ $1.982-2.466)$ and age $(\mathrm{OR}=1.064,95 \% \mathrm{CI}=0.861-1.219)$ were two independent predictors of stress ulcer. 


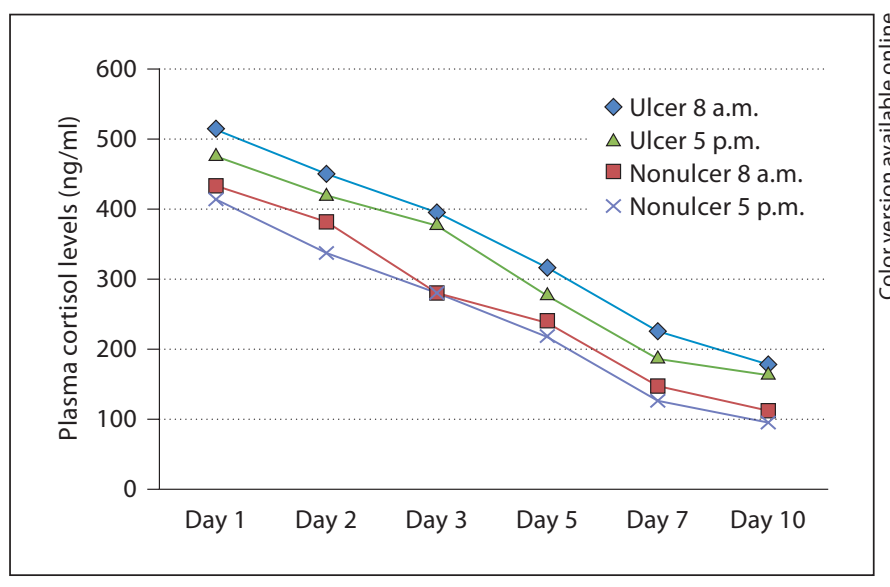

Fig. 1. The average values of plasma cortisol in patients with and without stress ulcer. From day 7 onwards, the values in the mornings and the afternoons had returned to the normal range (50$250 \mathrm{ng} / \mathrm{ml}$ ) in both groups.

\section{Discussion}

The major findings of this study are: (a) more than $44 \%$ of the patients with acute head trauma suffered from stress ulcer and gastrointestinal bleeding, and the presence of stress ulcer was associated with a higher mortality rate and a poorer recovery from the head or brain injuries; (b) in all patients, there was a significant increase in plasma cortisol levels within the first 3 days of head trauma and the plasma cortisol levels were inversely correlated with GCS scores; (c) the average levels of plasma cortisol in patients with gastrointestinal bleeding were higher than in those without stress ulcer. Plasma cortisol levels and the age of the patients were independent predictors of stress ulcer.

There is a close relationship between the severity of head injury and the incidence of gastric mucosal dysfunction [8]. In the present study, a lower GCS score was associated with a higher risk of stress ulcer and gastrointestinal bleeding. Although gastric acid hypersecretion appears to play a key role in the pathogenesis of stress ulcer $[8,16]$, increased secretion of some reactive hormones, such as adrenaline, noradrenaline, adrenocorticotropic hormone or cortisol may also be involved [14, 15 ] in this study because a majority of the patients with stress ulcer, $86.8 \%$, had an increased level of cortisol within a day of the trauma, and the average cortisol level was inversely correlated to the GCS scores, suggesting that plasma cortisol is associated with the severity of the head injuries.
There has been some indirect evidence on the role of cortisol in the pathogenesis of stress ulcer. In a rat model of cold-restraint stress, the rats that developed stress ulcer had a higher plasma level of cortisol than in the control [17]. Pretreating rats with clonidine inhibited gastric mucosal injury induced by cold-restraint stress and attenuated the cold-restraint-induced increases in cortisol levels [18]. Enhanced biosynthesis or release of cortisol may initially serve as effector signals and a protective mechanism in the response to stress [19]. However, excessive release of cortisol may be detrimental to the gastric mucosa. As shown in this study, the plasma levels of cortisol on day 1 of the head injury were an independent predictor of stress ulcer and gastrointestinal bleeding. Patients with stress ulcer had a higher mortality rate and poorer recovery from the trauma.

It is of interest to note that $2.9 \%$ of our patients had a plasma cortisol level below the normal reference range in the first week of the acute head injury. Although the plasma level of adrenocorticotropic hormone was not measured in these patients, the low level of plasma cortisol could be related to secondary adrenal failure due to adrenocorticotropic hormone deficiency [20].

A potential limitation of this study is that, due to ethical considerations, not all patients received endoscopic examination of the upper gastrointestinal tract. Therefore, patients with early-stage ulcerative pathology but no clinical bleeding might have been overlooked. However, this potential limitation probably had little adverse effect on the overall results of the study because our focus was on the relationship between clinically significant stress ulcer and the plasma cortisol levels. In addition, some proton pump inhibitors are known to increase plasma adrenocorticotropic hormone and cortisol [21]. However, omeprazole did not appear to have a significant impact on the hypothalamic-pituitary-adrenal axis [21]. The increase in plasma cortisol levels in our patients with stress ulcer was unlikely to be caused by omeprazole. Finally, other pituitary hormones such as thyroid-stimulating hormone, prolactin, or growth hormone were not assessed in this study. A previous report suggested that basal levels of prolactin in patients with stress ulcer were significantly higher than those of patients without stress ulcer, whereas the basal levels of thyroid-stimulating hormone and growth hormone were significantly lower [22]. The association between stress ulcer and other pituitary hormones in our patients is unclear.

Given the high prevalence of stress ulcer following acute severe head injury and the significant impact of stress ulcer on patient outcomes, primary prophylaxis 
against stress ulcer appears warranted. However, there is a lack of consensus with regard to appropriate prophylaxis regimens, although many trauma centers use histamine-2 blockers or proton pump inhibitors for such a purpose [23]. In the present study, older patients (e.g. $>38$ years old) and patients with high levels of plasma cortisol were more likely to develop stress ulcer. In addition, the majority of our patients with stress ulcer had a GCS score below 6 . It is possible that the prophylactic administration of proton pump inhibitors or histamine-2 blockers will benefit these high-risk patients the most in terms of stress ulcer prevention.

\section{Conclusions}

Acute severe head injury is associated with a significant increase in plasma cortisol within the first few days of the insult. The elevation of plasma cortisol is related to the severity of the head injury. The prevalence of stress ulcer was also increased in the patients with severe head injuries. Age and the plasma levels of cortisol seem to predict the prevalence of stress ulcer. These results may contribute to future development of primary prophylaxis for stress ulcer following acute severe head trauma.

\section{References}

1 Greenwald BD, Burnett DM, Miller MA: Congenital and acquired brain injury. 1 . Brain injury: epidemiology and pathophysiology. Arch Phys Med Rehabil 2003;84(suppl 1):S3-S7.

- Wu X, Hu J, Zhuo L, Fu C, Hui G, Wang Y, Yang W, Teng L, Lu S, Xu G: Epidemiology of traumatic brain injury in eastern China, 2004: a prospective large case study. J Trauma 2008;64:1313-1319.

-3 Hollaran LG, Zfass AM, Gayle WE, Wheeler $\mathrm{CB}$, Miller JD: Prevention of acute gastrointestinal complications after severe head injury: a controlled trial of cimetidine prophylaxis. Am J Surg 1980;139:44-48.

4 Lu WY: A review of stress ulcer prophylaxis in the neurosurgical intensive care unit. Neurosurgery 1997;41:416-421.

$\checkmark 5$ Kamada T, Fusamoto H, Kawano S: Acute gastroduodenal lesions in head injury. An endoscopic study. Am J Gastroenterol 1977; 68:249-253.

6 Kamada T, Fusamoto H, Kawano S: Gastrointestinal bleeding following head injury: a clinical study of 433 cases. Trauma 1997;17: 44-47.

7 Yu MK, Zhang GF, Jiang YJ, Zhu C, Lu YC, Song Y, Wu GH, Jiang ZW: Risk factor analysis of upper gastrointestinal bleeding after head injuries. Chin J Trauma 1996;12:375377.

8 Gudeman SK, Wheeler CB, Miller JD, Halloran LG, Becker DP: Gastric secretory and mucosal injury response to severe head trauma. Neurosurgery 1983;12:175-178.
9 Ott L, McClain CJ, Gillespie M, Young B: Cytokines and metabolic dysfunction after severe head injury. J Neurotrauma 1994;11: 447-472.

10 Clifton CL, Ziegler M, Grossman RG: Circulating catecholamines and sympathetic activity after severe head injury. Neurosurgery 1981;8:10-14.

11 McClain C, Cohen D, Phillips R, Ott L, Young B: Increased plasma and ventricular fluid interleukin- 6 levels in patients with severe head injury. J Lab Clin Med 1991;118: 225-231.

12 Venkatesh B, Townsend S, Boots RJ: Does splanchnic ischemia occur in isolated neurotrauma? A prospective observational study. Crit Care Med 1999;27:1175-1180.

13 Hsieh JS, Howng SL, Huang TJ, Wang JY, Chen FM: Endothelin-1, inducible nitric oxide synthase and macrophage inflammatory protein-1[alpha] in the pathogenesis of stress ulcer in neurotraumatic patients. J Trauma 2006;61:873-878.

14 Koiv L, Merisalu E, Zilmer K, Tomberg T, Kaasik AE: Changes of sympatho-adrenal and hypothalamo-pituitary-adrenocortical system in patients with head injury. Acta Neurol Scand 1997;96:52-58.

15 McArthur CJ, Gin T, McLaren IM, Critchley JA, Oh TE: Gastric emptying following brain injury: effects of choice of sedation and intracranial pressure. Intensive Care Med 1995;21:573-576.

$\checkmark 16$ Chan K, Lai ECS, Tuen H, Ngan JH, Mok F, Fan YW, Fung CF, Yu WC: Prospective double-blind placebo-controlled randomized trial on the use of ranitidine in preventing postoperative gastroduodenal complications in high-risk neurosurgical patients. J Neurosurg 1995;82:413-417.
17 Gitlin N, Ginn P, Kobayashi K, Arakawa T: The relationship between plasma cortisol and gastric mucosa prostaglandin levels in rats with stress ulcers. Aliment Pharmacol Ther 1988;2:213-220.

18 Yelken B, Dorman T, Erkasap S, Dundar E, Tanriverdi B: Clonidine pretreatment inhibits stress-induced gastric ulcer in rats. Anesth Analg 1999;89:159-162.

19 Bessey P, Downey RS, Monafo WW: Metabolic response to injury and critical illness; in Civetta JM, Taylor RW, Kirby RR (eds): Critical Care, ed 3. New York, LippincottRaven, 1997, p 325.

20 Tanriverdi F, Ulutabanca H, Unluhizarci K, Selcuklu A, Felipe F, Casanueva FF, Kelestimur F: Pituitary functions in the acute phase of traumatic brain injury: are they related to severity of the injury or mortality? Brain Inj 2007;21:433-439.

21 Katagiri F, Inoue S, Sato Y, Itoh H, Takeyama $\mathrm{M}$ : Comparison of the effects of proton pump inhibitors on human plasma adrenocorticotropic hormone and cortisol levels under the starved condition. Biomed Pharmacother 2006;60:109-112.

22 Hwang SL, Lieu AS, Howng SL, Hsieh JS, Huang TJ: Hypothalamic dysfunction in acute head-injured patients with stress ulcer. Kaohsiung J Med Sci 1998;14:554-560.

23 Barletta JF, Erstad BL, Fortune JB: Stress ulcer prophylaxis in trauma patients. Crit Care 2002;6:526-530. 